\title{
PROSTORNI PRERAZMEŠTAJ STANOVNIŠTVA I NJEGOVE IMPLIKACIJE NA RAZVTTAK NASELJA U SR MAKEDONIJI
}

\author{
Mitko Panov*
}

IZVLEČEK

UDK 911.37:312.8(497.17)

Problematika deagrarizacije in urbanizacije $v$ Makedoniji s posebnim ozirom na migracije prebivalstva je prikazana na osnovi podrobnih proucevanj.

\section{ABSTRACT}

UDC 911.37:312.8(497.17)

MOVEMENT OF THE POPULATION AND ITS IMPLICATIONS OVER COLONIES DEVELOPMENT, WITHIN SR MACEDONIA

On the basis of detailed analyisis the author presents the problems of deagrarization and urbanization in the SR Macedonia with special emphasis on migration of population.

Prerazmestaj stanovništva u SR Makedoniji putem migracija na relacijama selo grad i grad - grad, odnosno u granicama jedne opštine ili izmedju opština, $\mathrm{t}$. regiona i vecih prostornih celina, dovelo je do veoma ozbiljnih ne samo populacionih već i socio-ekonomskih problema i teskih posledica. Uzimajuci u obzir vremensku komponentu, prostorna populaciska degresija uglavnom je zapođela u novije doba, tj. od pre nekih tridesetak godina. Prateci razloge, stanje i posledice nijc teß̌ko utvrditi preciznim faktima te na pretpostavkama, sto je od bitnog znacaja i za iznalaženje prakticnih mera za rešavanje problema iako se u tom smislu dosta kasni i nedovoljno priziva u pomoc nauka.

Posledice prerazmestaja stanovništva su različte, viß̌e slučajeva negativne, jer su migracije uglavnom stihijne a ne planski usmerene i sinhronizovane. U SR Makedoniji ima danas na jednoj strani, depopulaciona podrux ja, sa jako nepovo!jnom demografskom strukturom stanovništva, a na drugoj, prenaglašena koncentracija stanovniకtva u gradovima i u nekoliko podruxja zapadne Makedonije. Zbog toga, više od 80 \% stanovništva živi u gradovima i ravniðarskim podruxjima, a manje od $20 \%$ na dve trccine prostora, sto upozorava na nepovoljno stanje naseljenosti. Prema tome urbanizacija u Makedoniji je već optimalna i ima oblik hipcrurbanizacije, o cemu ce biti reci kasnije, a u ruralnoj sredini deagrarizacija je zahvatila takve razmere, da se vec jedna trexina, ili vise od 200.000 hektara obradive površne ne obradjuje ili se racionalno ne koristi. Dalje, prerazmestajem stanovnistva u nekim podruxjima zapadne Makedonije, a naroxito u Poloskoj Kotlini, gde živi najveci broj albanskog stanovništva u Republici, stvaraju se homogene etnixke zone itd.

\footnotetext{
* Dr., red.univ.prof., Odsek za geografiju PMF, 91000 Skopje, Gazibaba 1, YU
} 
Cilj našg daljeg izlaganja je ukazati kako migraciona kretanja uticu na populaciski, teritorijaini i funkcionalni razvitak naselja, jer se u tom smislu i najviše vide promene u prostoru, sa najvecim problemima. Pre svega prerazmestaj stanovništva naroxito utice na promene populaciske velične seoskih i gradskih naselja, a time i neposredno na njihov celokupni razvitak. Znatan broj seoskih naselja je sasvim raseljen, druga su u fazi rascljavanja, treça populaciski rastu preko optimuma sto im pruža njihov atar za agrarnu egzistenciju, dok je u ruralnim zonama sve manja razlika izmedju sela i grada. U gradovima je prisutan znatan mehanixki priliv stanovništva sa velikim razlikama medžu gradovima. U većim gradovima gde je imigracija izraženija, sve se viß̌e osvaja obradivo na račun gradjevinskog zemljista, sire se prigradske zone, divogradba pa i nazovimo ih "elitne" zone. Urbana sredina je sve viß̌e podložena Štetnim uticajem raznih zagadjivaca kao sto je tipican slucaj sa Skopjem i T.Velesom. Sa doseljavanjem, naroxito mladog stanovnistva, u gradovima se permanentno povećava broj nezapošljenih i sa tim povezani socijalni problemi itd.

Poðećemo izlaganjem sa seoskim naseljima, nezalazeci opisno u uzroce nepovoljnih promena u rurainoj sredini SR Makedonije. Mreža scoskih naseija se razredjuje. Masovnija emigracija seoskog stanovništva zapocela je beže posle 1961 godine. Prema podacima iz 1971 godine sela su napustila oko 270.000 lica, u periodu 1971 - 1981 godine, emigracija je nešto smanjena ali je ipak još dosta aktualna. ${ }^{1}$ Interesantno je to కto su do 1971 godine višc bila izražena regionalna iseljavanja najviše u vece gradske centre, dok su u periociu od 1971 do 1981 godine bile aktivnije lokalne migracije, pa su zbog toga i manji gradovi pođeli populaciski brže da rastu. Zbog ovakvog masovnog prerazmeštaja seoskog stanovništva, prvi put u istoriji naseljenosti SR Makedonije, u 1981 godini broj seoskog stanovništva je bio manji od gradsog, seoskoj $44,9 \%$, a gradskoj $55,1 \%$. Da codamo i jedan iznenadjuci podatak da je od ukupno 1636 scla, u SR Makedoniji 1981 godine, u viక̌e od 1000 seoska naselja broj stanovniStva opao u odnosu na 1971 godinu, dok su 106 sela sasvim raseljena.

Zbog gornjih uzroka nastale su znaxajne promene u velicini seoskih nasclja. U suštini je veoma porastao broj malih sela, do 300 stanovnika. Tako je bilo u 1981 godine 837 ili $51,5 \%$ malih sela, a to nije broj za potcenjivanje, pogotovu kada se $z n a$, da se u odnosu na 1961 godinu brcj malih scla povecao za 265 nasclja. U 1981 godini u ovim malim selima bilo je 107.096 stanovnika ili $12,5 \%$ od ukupne seoske populacije u Republici. To ukazuje, da je u polovini seoskih naselja živela samo jedna osmina seoskog stanovništva Republike $\mathrm{i}$ to sa nepovoljnom demografskom strukturom. Sva

\footnotetext{
${ }^{1}$ Statistið̌ki podaci korisceni su iz sledecih publikacija: Prvi rezultati od popisot na naselenieto vo 1971 godina, Republicki zavod za statistiku, Statistiðki pregled 17, Skopje, 1971; Prvi rezultati od popisot na naselcnicto i domakinstvata vo 1981 godina, RZS, Statisticki pregled 115, Skopje, 1981 godina; Naselenie vo gradovite na SR Makedonija 1948-1981, RZS, Statisticki pregled 162, Skopje, 1986.
} 
su ova sela zahvacena intenzivnom deagrarizacijom, a povrSina obradivog zemljista na starima ovih sela nije mala. Raspored malih sela po pojedinim podrux jima je razlican u zavisnosti od intenziteta migracionih kretanja. Tako se opštine Titov Veles, gde je emigracija seoskog stanovništva znatna, 60 od ukupno 80 sela su mala, a na teritoriji opstine Tetovo, gde je za sada emigracija seoskog stanovniłtva mala, 10 od ukupno 89 sela su mala. ${ }^{2}$

Drugu grupu cine velika sela sa više od 800 stanovnika. Takvih je u 1981 godini bilo 303 ili $18,4 \%$ sela u SR Makedoniji, dok je više od po 2000 stanovnika živelo samo u 76 naselja. U ovim relativno velikim selima u 1981 godini ukupno je živelo 483.888 ili $57,5 \%$ seoskog stanovništva republike. To znaci, da u nešto manje od jedne petine sela žive viße od polovine seoskog stanovništva SR Makedonije. U ovim selima stanovnistvo se je povećalo glavno prirodnim prirastajem. Medjutim postoje sela u kojima ima i dosta doseljenika, naroxito u opstinama Tetovo i Skopje u kojima su se naselili migranti iz SAP Kosova, $t \mathrm{j}$, albansko stanovništvo i muslimansko stanovništvo iz Sandjaka. Jedan deo velikih sela, uzimajuci u obzir nepovoljan odnos strukture domacinstva prema poljoprivrednim povrSinama, je već agrarno prenaseljen i ako se na vreme ne reši pitanje njihovog daljeg razvitka, naročito putem disperzije neagrarnih delatnosti u njima, postoje potencijalne mogućnosti za jacu cmigraciju seoskog stanovništva. Naroxito brojne su agrarno prenaseljena naselja u opstinama sa albanskim stanovnistvom Tetovo, Gostivar, Debar i Kiðevo u kojima su 92 seia ili $75,4 \%$ svih agrarno prenaseljenih sela u SR Makedoniji (122).

Iz gornjeg sc vidi da je u ruralnoj sredini SR Makedonije, zbog prerazmeštaja stanovniStva, nastao veoma ncravnomerni razmeStaj seoskog stanovnistva po naseljima ili pojedinim podruxjima, tc se zato proces deagrarizacije intenzivno Siri, a prisutna je i problematika agrarno prenaseljenih naselja. Medjutim, ako se ostane samo na ovoj zabrinjavajucoj konstataciji, problem se nece sam rešiti. Potrebno je oceniti i odrediti dalji razvitak scoskih naselja, Sto je i jedan od ciljeva ovog kratog rada.

Govoriti o objektivnoj perspektivi razvoja sela nije jednostavno, narocito u sadasnjim prilikama loß̌g socio-ekonomskog stanja veceg dela ruralne sredine. Tacno zbog toga potrebna su fundamentalna i praktix̌na istraživanja mreže seoskih naselja. U tom smislu obratili smo naroxitu pažnju na đetiri osnovna clementa: odnos nasclja prema odredjenim prostornim determinantama, na strukturalne promene seoskog stanovnistva, na funkcionalnu klasifikaciju svakog sela i na odredjivanje ruralnih podrux ja i ruralnih centara. Svaki od ovih cetiri elemenata vet je detaljno razradjen ali u ovom radu iznecemo samo nekoliko kratkih informacija.

\footnotetext{
${ }^{2}$ M.Panov: Populaciski i prostorni obelcžja i problemi na malite sela vo SR Makedonija. Institut za prostorno planiranje - Ohrid, Skopje, 1983.
} 
U vezi prostornih determinanti, prouxili smo razmeštaj seoskih naselja u odnosu na orografske prilike te u tom smisiu jasno konstatirali da u SR Makedoniji ima 525 ravnixarskih, 764 brdskih i 347 planinskih naselja. U odnosu na saobraćajnu mrežu, veoma mali broj sela, nešto više od 100 , leži na glavnim putevima, a veliki broj naseIja dosta je od njih udaljen. Mali broj sela (oko 80 ) leži u takozvanoj ruralnoj ili najbližoj zoni prema gradovima, a veliki broj sela je dosta udaljen od centralnih mesta. Ove prostorne determinante jasno ukazuju zasto je prerazmestaj stanovništva bio intenzivan i da se najudaljenija sela najviße raseljavaju.

Mi smo na osnovu odredjenih kriterija izvrSili funkcionalnu klasifikaciju svih sela u Republici. Interesantno je, da smo sva sela odredili u 7 funkcionalnih grupa, sa tom napomenom, da najveći broj, 555 naselja pripadaju grupi sa ratarskom funkcijom, 321 nasclje grupi sa ratarsko-stoðarskom funkcijom, a najmanje, 13 seia, pripadaju grupi sa šumarskom funkcijom.

Za stabiiniji razvitak seoskih naselja, za održanje coveka u prostoru i za produktivniju poljoprivrednu proizvodnju, smatrali smo da je veoma važno, da se u ruralnoj sredini izvrši podela po ruralnim podrux jima, sto je od dragocene koristi za drustveno a naroxito za prostorno planiranje. U tom smislu, uzimajuci u obzir nekoliko kriterijuma (priroda prostora, prostorne determinante, populaciske prilike, agrarnu strukturu i cr.) izvršili smo detaljnu podelu u svim opštinama u SR Makedoniji i odredili tačan broj u svakoj od njih. Ukupno za celu Republiku odredili smo 221 ruralna podrux ja, a to znaxi $i$ isti toliki broj ruralnih centara. Izvrsili smo i funkcionalnu klasifikaciju svakog podrucja, a zatim i objasnili kakvu ulogu treba da imaju ruralni centri prema funkcionalnom obeležju područja. Za svako ruralno područje odredjenje su njegove granice, broj sela u njima, stanje demografske strukture stanovnixtva i agrarna struktura, కto je zahtevalo veoma strpljiv i mukotrpan rad.

Na osnovu prethodno navedenih četiri elemenata smo za dugoročniji socioekonomski razvitak ruralne srcdine, kao i za urbanisticko uredjenje sela, izvršli jednu praktixnu rangirenje i selekciju u mreži seoskih naselja, i to ne samo u globalu vec i za svaku opstinu i svako ruralno podrucje. Prema tome hitan prioritet u razvoju treba da ima 566 sela, 809 sela treba da se održi, tj. treba preuzeti mere da se ne dozvoli njihovo potpuno rascljavanje, već naprotiv da se revitaliziraju, dok 261 sela treba da se rasele jer ona danas skoro nemaju ckonomskog opravdanja da postoje. U tom smislu razradili smo način kako da se ona rasele a da se poljoprivredne povrŠne na njihovim atarima, koje iznose 310.971 ha, racionalno koriste, odnosne da se ne transformiraju u divlji pejsaž kao sto je to danas vidno. U tom smislu odredili smo takozvana 75 integralna jezgra, odnosno sabirna naselja.

Iz dosadašnjeg izlaganja može se izvesti kratak zakljuðak da je zbog intenzivnog 
prerazmestaja stanovništva, naroxito seoskog, došlo do znatnog i skoro kaotixnog poremecaja u mreži seoskih naselja. Iako se dosta kasni, za saniranje nepovoljnih socio-ekonomskih prilika u ruralnoj srednini SR Makedonije, mere za dugorocni i planski razvitak seoskih naselja ne bi bile celishodne i sigurne bez proucavanje navedenih elemenata. To je na odredjen naxin savremena novina, barem za SR Makedoniju, i to ne samo sa koncepciskog vec i jos više praktix̌nog aspekta i značaja.

Prerazmestaj stanovnistva uticao je i utice na populaciski i teritorijalni razvitak gradova. U suštini svi 29 gradovi u SR Makedoniji su imigraciska mesta jer je gro migranata upucen prema njima. Tako su sva gradska naselja populaciski dosta narasla, i urbanizacija u SR Makedoniji 1981 godine bila je najizraženija u našoj zemlji. Medjutim urbanizacija po svom tipu ima viłe kvantitativan karakter jer su doseljenici većinom sa sela. U suštini takva hiperurbanizacija, za ekonomske prilike u SR Makedoniji nije povoljna. U 1981 godini u gradovima živelo je 1.054 .809 ili $55,1 \%$ stanovnika, a u sclima 858.762 ili $44,9 \%$ stanovnika stanovnistva Republike.

U svim gradovima prisutan je mehanički priliv stanovništva, u nekima manje a u drugima vise, te zato se oni danas razlikuju po velicini. Tako grad se racuna i Pehとevo sa oko 3.000 stanovnika i Skopje sa 405.874 stanovnika, ili Kratovo sa 5.420 i Bitola sa 80.832 stanovnika, pa zato su i problemi njihovog razvitka razlixni i sa razlicitim implikacijama u pojedinim urbanim sredinama. Jedan od osnovnih faktora zasto postoje znatne razlike u naseljenosti, je u vezi sa prostornim razmeštajem gradova. Jedni gradovi imaju lokalni jli periferan položaj u odnosu na nekoliko glavnih komunikacija i ogranixene gravitaciske sfere uslovljene i prirodom prostora. To su uglavnom mali gradiči a takvih ima 13 i u sadašnjoj fazi prerazmeštaja stanovništva pona§aju se kao etapne stanice iz kojih teku migracije prema vecim gradovima, ali se u poslednje vreme imigranti sve viłe zadržavaju u njima. Drugu grupu cini 9 gradova koji imaju regionalni položaj, sa nešto proširenim gravitacionim sferama i izvan granica njihovih opština u kojima je imigracija znałajna ali ipak još ne mnogo velika. Treću grupu cine 6 gradova koji imaju interregionalni položaj, koji su funkcionalno najrazvijeniji, sa Sirokim gravitacionim zonama te su zato i najprivlacnija imigraciska mesta. Za razliku od gornjih grupa gradova, Skopje ima specifican ne samo interregionalni već i republicki i medjunarodni položaj i značaj, sa najvecom koncentracijom sekundarnih i tercijarnih delatnosti, pa zato danas u njemu živi jedna Cetvrtina od celokupnog stanovništva SR Makedonije, sto svakako nije za pohvalu ako se uzme u obzir da SR Makedonija broji oko dva miliona žitelja. U giobalu je u periodu 1971 1981 godine, migracioni saldo u malim gradovima iznosio $11,0 \%$, u srednjim $37,0 \%$ a u većim gradovima zajedno sa Skopjem $52,0 \%$ od ukupnog migracionog salda u svim gradovima u Republici.

O funkcionalnoj klasifikaciji gradova nece biti govora, jer to nije cilj ovog rada, ali 
da funkcije uticu na migraciona kretanja, na razlixite socioekonomske i druge probleme u gradovima je bezsporan fakt. Medjutim, obraticemo pažnju na one vidne implikacije koje su u uskoj vezi sa mehanixkim prilivom stanovnistva, $\mathrm{tj}$. na teritorijalno Sirenje gradova, na stvaranje etnicki homogenih zona i na neke socijalne probleme.

Svi gradovi u SR Makedoniji pod pritiskom imigranata teritorijalno se Sire van centralnog gradskog jezgra i to tako brzim tempom da su i najnoviji urbanisticki planovi već zastarcli, ili u većini slučaja malo se poštuju. Gradovi se prostorno šire legalnim putem, tj. prema postoje $\chi_{i m}$ urbanistickim planovima, zatim nelegalno putem divogradbe i stvaranjem specifiðnih perifernih i takozvanih "elitnih" zona. Medjutim u svim sluðajevima prostornog Sirenja zauzimaju se prigradske agrarne povrSine. A poznato je kada se jednom obradivo zemljiste transformira u gradjevinsko ono je za uvck i nepovratno izgubljeno za poljoprivredu. Nažalost i legalnim putem, tj. prema urbanistixkim pianovima zahvataju se uglavnom ravničarski delovi, sa najboljim bonitetom zemljista. Takav je tipixan primer sa Skopjem. U sustini u ravniðarskom deiu Skopske kotline, prema katastaru, registrirano je 5000 ha zemljista sa najboljom, pryom i drugom klasom boniteta. Medjutim, zbog velikog mehanickog priliva i potrebom za stanovanje, kao i izgradnjom nekoliko velikih fabrika na južnom i jugoistoEnoin delu grada, tj. u ravnici, novim prostornim Sirenjem grada zauzeto je 3000 ha najkvalitetnije obradivog zemljista. To je $60 \%$ od ukupnog takvog zemljista u celoj Skopskoj kotlini, a to zemljiste nekada je snabdevalo Skopje sa povrtarskim i vocarskim proizvodima. Rigorozan je primer osvajanje prigradskog agrarnog zemijista za račn gradjevinskog u Kumanovu kome su već pripojena i nekoliko rajbližih sela. Slǐna je situacija u Tetovu, Gostivaru, Kiðevu, Prilepu, Strumici i drugim gradovina. Kada bi se prerałunala povrßina transformiranog agrarnog u gradjevinsko zemljište za sve gradove u SR Makedoniji, dobila bi se takva brojka izgubljenog visokokvalitctnog zemljišta, koja nije uopšte za potcenivanje.

Pod uticajem nekontroliranog priliva imigranata, raroxito sa sela, gradovi se prostorno šre i neiegalnim putem, $\mathrm{t}$. divogradbom. Taj problem je jako prisutan, aktualan $\mathrm{i}$ razume se veoma nepovoljan, narocito za nizak standard stanovanja, jer su lokaliteti divogradbe komunaino slabo opremljeni i neregulirani urbanistickim planom. Divogradbe mogu da nicu takoreci preko noci, na periferijama gradova, na strmijem mikroreijefu. Medjutim to nije pravilo za sve gradove jer se divogradbe javljaju i na povoljnijem, ravnicarskom terenu, kao i pojedinc kuce unutar medjuprostornim deiovina grada. U ovon smislu najbolji je primer Skopje koje je sa svih strana takoreci opkoljeno divogradbama, a narocito u prigradskim naseljima, te je zato površina naseljenog prostora šra u odnosu na ukupnu populaciju. Veoma su specificni sluxaji Tetova, Gostivara, Kumanova i Kixeva u kojima je veliki priliv albanskog stanovništva iz okolnih scla i iz SAP Kosova. Tako, na primer, u Tctovu naseljen prostor 
veoma se je prosirio na istoðnoj i zapadnoj strani kucama albanskih doseljenika sa i bez dozvole gradnje. U Gostivaru mnogo kuca je izgradjeno na jako plodnom prigradskom agrarnom zemljistu, a u Kið̌evu gradska površina je otiß̌la daleko od nekadašnjeg uskog centra, cak do niskih, tj. prelaznih padina Bistre. Iako postoji zakon o koriscenju zemljista on se, barem do sada, malo poštuje. U manjim gradovima veća je kontrola u vezi divogradbe kao, na primer, u Negotinu na Vardaru gde skoro nema divo naseljenog lokaliteta, pa cak ni kuca. Ovakav proces prostornog sirenja gradova je najnepovoljna posledica mehanixkog priliva, glavno seoskog stanovništva, a u gradovima gde živi znałajan broj albanskog stanovništa uzrok divo gradbi je i obiðajno pravo da za svakog muškog potomka bude izgradjena posebna kuća.

U gradovima sa razlixnom etnixkom strukturom stanovništva prisutna je pojava stvaranja homogenih etnixkih delova. To je naročito izraženo u onim gradovima gde su imigranti albanskog ili romskog porekla. Takvih primera ima u Skopju ali narocito u Tetovu gde su formirane cele mahale iskljucivo naseljene Albancima i to glavno sa SAP Kosova, a u tom smislu ne zaostaje ni Kumanovo. Vecinom kuca je izgradjeno na divo, ali ima primera gde se stanovi ili kuce otkupljuju za pozamašnu sumu novaca da bi se nealbanska domacinstva iselila u druge delove grada.

Na kratko želimo da obratimo pažnju i na socijalne probleme koji su u največoj meri uzrokovane vecim prilivom imigranata u gradove SR Makedonije. S obzirom da je gro doseljenika sa sela $\mathrm{i}$ da je većina od njih nekvalifikovano i sa niskim obrazovanjem, znatno se je povećao broj nezaposljenih lica a tim u vezi socijalne posledice. Medjutim, želimo da ukažemo na neke sociološke aspekte koji su do sada, barem u SR Makedoniji, malo obradjene u sociogeografskim istraživanjima. U prigradskin naseljima i u delovima divogradnje, socijalna struktura gradjana i način njihovog življenja je specifiðan. Ovde uglavnom žive radnici i doseljenici sa sela, sa malim liðnim dohodkom, sa nižim kvalifikacijama, sa nižim stepenom obrazovanja, sa znatno vecim izdacima u prevozu do gradskog centra, sa slabom komunalnom opremljenoscu, uopšte sa nižim životnim standardom, da ne kažemo siromašniji sloj gradskog stanovniStva. S druge strane, pak, u odredjenim delovima grada, a naročito u Skopju ima, nazovimo ih "elitne zone" sa suprotnim uslovima življenja, tj. sa boljim životnim standardom, sa većom komunalnom higijenom, sa konfornim kućama i raznim drugim privilegijama. Medjutim, ako se prouxi socijalno poreklo i struktura tih gradjana u "elitnim zonama", ili kako se barem do sada imenuju kao "mocnici", a što je dosta teško doci do takih podataka, onda se može postaviti pitanje dali je opravdano postojanje socijalne diferenciacije zona stanovanja.

Prema ovome sto je dosada rečno u vezi prerazmestaja stanovnistva, $t \mathrm{j}$. o migracijama i njihove razliene implikacije na razvitak naselja, može se kratko zakljuxiti siedece: ova problematika je veoma aktualna i ona zaslužuje pažnju još detaljnijeg 
prouðavanja, iz izvedenih objektivnih konstatacija praktiðno treba da se iznadju resenja koja bi brže mogla uticati na daleko bolji razvitak kako ruralne tako i urbane sredine, ali pri tome nauka treba da dobije primat koji je za sada bio samo simboliŁan. Negativne socio-ekonomske posledice, prouzrokovane glavno emigracijom seoskog stanovništva, treba ublažiti ili sasvim otkloniti novim planskim razvojem mreže seoskih naselja. Neophodno je sankcionirati stihijni proces urbanizacije. Nije u pitanju samo prenaglaseni kvantitet urbanizacije vec, kao sto se vidi iz nekih delova rada, pitanje je kako smanjiti vremenski period prelaska kvantiteta u kvalitet, a to znaci i smanjiti još postojece klasiæne razlike izmedju sela i gradova. 


\section{MOVEMENT OF THE POPULATION AND ITS IMPLICATIONS OVER COLONIES DEVELOPMENT WITHIN SR MACEDONIA}

The basic goal, in the work, is to show and to analyze the influence of the population movement over the Colonies Development, within SR Macedonia. In fact, the question is about the migration movements, as an important factor the of population's, territorial's and functional development, both for villages and city colonies. Taking into consideration the fact, that the migrations, mainly are moving elementally, so on one side can be seen an expressive depopulation area, characteristical for rural environment, and on the other side, the settlement concentration is much bigger on a smal area, characteristical for urban region. This is the reason that from 1981, about $80 \%$ of the total population in SR Macedonia lives in the cities, as on two thirdsof the Republic lived $20 \%$, with very bad demographical structure.

The implications of this movement are noted, mainly, over the colonies.

In the first part, the question is about the colonies, that is, in the brief introduction a description is given for the movement of the rural environment, from which thousand of peoples emigrated into the cities, and for the first time, in 1981 was noted that the village's settlement became smaller, in the comparison with the cities settlement, that is, $44,9 \%$ of the total settlement in the Republic.

From the analises we conclude that the villages settlement are particularly changed due to the mentioned migration. Namely, the number of the small vilages has been rapidly changed (to 300 populaltions): while, in 1981, there were 837 colonies, or 51,5 $\%$ of the total villages number within the republic. The snall villages, now became a big problem.

Regarding the villages, that is, the planning of the net development of the village colonies, four elements are taken into consideration:

1. Colonies relations towards some space determinants.

2. Structural changements of the village population

3. Functional clasification of the villages and

4. Determination of the rural areas and rural centres.

All these four elements are shortly analyzed and proved with factographical material.

In the third part of the work, required details about problematic are given especially of the migration movement aspect. 
In fact, all 29 cities, within SR Macedonia, more or less, are migration centres, therefore, in 1981 the cities colonies were $55,1 \%$ of the total Republic settlement and urbanisation process, in relation to all Republics in Yugoslavia was the bigger one.

This appearance can't be qualified as a positive one, particularly not for Skopje, where, today lives one fourth of the total Settlement in the Republic. Due to the big mechanical influx into the city an attention is paid towards three elements which were analised:

1. Territorial cities expanding

2. Appearance of ethnic homogenous zones and

3. Some social problems.

Regarding the territorial expansion, legally, that is, in accordance with Urban Plans, or illegally with a great number of illegally made buildings, an information is given that a part of new made buildings is on the agrarian land and a good quality field is lost for ever. Due to a great number of the Albanian immigrants, that is, immigrants from Albanian origin, in some Cities, as Skopje, Tetovo, Kumanovo and other, clear ethnic parts are already made.

Regarding the social problem, besides the big unemployment, a particular point is given social structure of settlement especially those living at the suburban areas on the "clite" zone. 